\title{
Protein Kinase C inhibitor Molecule Effect Partial Reversal of Spliceopathy in Myotonic Dystrophy Type 2 Cell Line
}

\author{
Inyang U. Udosen \\ Department of Genetics \& Biotechnology, Akwa Ibom State University, Nigeria
}

\begin{abstract}
Myotonic dystrophy is a neuromuscular disease which manifest as two forms namely type 1 (DM1) and type 2 (DM2). One of the major molecular events associated with the disease condition is misregulation of splicing resulting in spliceopathy. This study was performed to assess the effect of protein kinase $\mathrm{C}$ (PKC) inhibitors- Ro 31-8220 and hypericin- on the splicing of insulin receptor (IR) and muscleblind-like (MBNL1) in myotonic dystrophy type 2 (DM2) cell line. The results of this study demonstrated that only Ro 31-8820 was able to effect partial rescue of missplicing of insulin receptor and muscleblind-like 1. It indicates that it could be a possible therapeutic agent for treatment of DM2.
\end{abstract}

Keywords: Myotonic dystrophy, Protein Kinase C inhibitor, spliceopathy, therapeutics

DOI: $10.7176 / \mathrm{JNSR} / 11-14-03$

Publication date:July $31^{\text {st }} 2020$

\section{INTRODUCTION}

Myotonic dystrophy (DM) is the most common form of muscular dystrophy in adults and is inherited as an autosomal dominant neuromuscular disease (1). There are two forms of DM namely: myotonic dystrophy type 1 (DM1) and myotonic dystrophy type 2 (DM2). DM2 is less common and shares similar disease phenotype as well as molecular phenotype with DM1 (1). It differs from DM1 by having the absence of congenital forms in DM2, mode of muscle weakness, and very little association of the nervous system with DM2 (2). Disease symptoms associated with DM2 include myotonia and slight muscle weakness in proximal muscles. The molecular basis for DM2 mutation is an unstable CCTG repeat expansion in intron1 of the zinc finger protein 9 gene (ZNF9), formerly referred to as $C N B P$ (3). The repeat tetranucleotide expansions in DM2 ranges from 75-11000 units (1).

One of the RNA binding proteins proposed to interact with expanded repeat transcripts to form nuclear foci is muscleblind-like proteins (MBNL). The MBNL has been shown to colocalise with expanded CUG or CCUG repeats in nuclear foci $(4,5,6)$.

MBNL1, MBNL2 and 3 were found to colocalise with RNA foci in DM1 and DM2 cells $(5,6,7)$. The strategy for potential DM therapy would be inhibition of expanded repeats transcripts to prevent its interaction with muscleblind-like protein in order to make it available for cellular functions of regulating alternative splicing.

Several studies have been carried out to identify inhibitors that can bind to expanded CUG or expanded CCUG repeat RNA to prevent its interaction with muscleblind-like proteins $(8,9,10,11)$.

One of the major molecular features of DM is misregulation of alternative splicing. It has been reported that MBNL1 depletion leads to misregulation of splicing in many genes and in some cases, it resulted in DM phenotypes (12).

In DM, misregulation of alternative splicing occurs in some splicing events that are normally developmentally regulated and in the disease, they fail to express the adult isoform mRNA in adult tissues. The developmental regulation of transcripts could be absolute (involving exon 22 of SERCA1, exon 7 of MBNL1, exon 11 of ZASP, exon5 of $c T N T$ ) or partial (in $I R$ exon11, MBNL2 exon7). Instead the foetal mRNA and protein is expressed which cannot function in adult tissues resulting DM phenotype.

Myotonia and insulin resistance which are major symptoms in DM are associated with splicing misregulation of muscle-specific chloride channel $(C L C N-1)$ and insulin receptor $(I R)$ respectively.

The insulin resistance found in DM is associated with inability to express $I R$ splice variant (IR-B) that normally occurs in adult skeletal muscle. Instead, DM patients express the nonmuscle $I R$ isoform (IR-A) which has a lower signalling ability than those expressed in adult skeletal muscle and the expression of this isoform in DM skeletal muscle cultures has been implicated in the decreased responsiveness to insulin compared to control cultures from unaffected individuals $(13,14)$.

Other studies have suggested the involvement of a misplicing event in myotonic dystrophy that involves Zband alternatively spliced PDZ-domain protein (15,16), CYPHER (16) and in dystrophin (17).

Other misregulated splicing events observed in DM include those involving cardiac troponin T (18), tau (19), myotubularin-related protein 1 (20), fast skeletal troponin T (21), SERCA1 and SERCA2 (22).

Correction of splicing abnormalities has become a potential target for therapeutic intervention in DM.

In this study, Protein Kinase C inhibitors (Ro 31-8220 and hypericin) which was previously identified in therapeutic screening study to disrupt interactions between MBNL proteins and expanded repeat units to prevent foci formation in DM2 cell lines (23) was used to study its effect of correction of splicing misregulation of $I R$ and 
$M B N L 1$ in DM2 fibroblast cell lines.

\section{MATERIALS AND METHODS}

Cell lines used in the study a DM2 fibroblast and a wild type (WT) line. All human fibroblasts used in this study had been previously telomerised. Cells were cultured in Dulbeccos Modified Eagle's Medium (DMEM) containing $10 \%$ Foetal Bovine Serum (FBS) with Penicillin/Streptomycin.

For compound treatments, cells were treated with compounds in T-75 flasks. The concentrations of $100 \mu \mathrm{M}$, $48 \mu \mathrm{M}, 8 \mu \mathrm{M}$ and $1.6 \mu \mathrm{M}$ were used. Compounds used for treatments were Protein Kinase C (PKC) inhibitors- Ro 31-8220 and hypericin with Dimethyl Sulphoxide (DMSO) as control

Total RNA was extracted from cell and fibroblast lines and utilized for cDNA synthesis using random hexamers and reverse transcriptase from New England Biolab. One microlitre of the synthesized cDNA was subsequently used for PCR as follows:

For insulin receptor splicing analysis, amplification was carried out using $1 / 20^{\text {th }}$ of the synthesized cDNA with forward primer (IRfor) with sequence 5'CCAAAGACAGACTCTCAGAT3' and reverse primer (IRrev) with 5'AACATCGCCAAGGGACCTGC3'. Thirty cycles of PCR was performed, consisting of denaturation at $95^{\circ} \mathrm{C}$ for 5 minutes, followed by repeating cycles of $95^{\circ} \mathrm{C}$ for 30 seconds; annealing at $60^{\circ} \mathrm{C}$ for 30 seconds; and extension at $72^{\circ} \mathrm{C}$ for 30 seconds. This was followed by a final extension of $72^{\circ} \mathrm{C}$ for 5 minutes. RT-PCR products were resolved by electrophoresis on 3\% agarose gels with bands scanned under UV light. For quantification of insulin receptor isoforms, a fluorescently-labelled primer (IRflp) was used as the forward primer and PCR products was analysed on Genescan following 26 cycles of amplification.

For $M B N L 1$ splicing, $1 / 20^{\text {th }}$ of cDNA was amplified with primers: MBNL1for5'GCTGCCCAATACCAGGTCAAC3' and MBNL1rev 5'TGGTGGGAGAAATGCTGTATGC3' at 30 cycles consisting of denaturation at $95^{\circ} \mathrm{C}$ for 5 minutes, repeating cycles of $95{ }^{\circ} \mathrm{C}$ for 30 seconds; annealing at $62^{\circ} \mathrm{C}$ for 30 seconds; and extension at $72{ }^{\circ} \mathrm{C}$ for 45 seconds. Final extension was performed at $72{ }^{\circ} \mathrm{C}$ for 5 minutes. Quantification of $M B N L 1$ splice isoforms were performed at 22-24 cycles using fluorescently- labelled MBNLfor primer.

RT-PCR were normalised using GAPDH with forward primer GAPDHf5'GATGACAAGCTTCCCGTTCTCAGCC3' with GAPDHrev- 5'TGAAGGTCGGAGTCAACGGATTTGGT3' as the reverse primer.

\section{RESULT}

One of the major molecular features of DM is misregulation of alternative splicing. To test the relevance of this concept; two misregulated splicing events associated with DM was utilized for this study. The splicing abnormality used for the study was that involving insulin resistance and muscleblind protein 1 to assess the effect of compound treatments on reversing the splicing abnormality. Missplicing of insulin receptor causes insulin resistance observed in DM patients (14). The insulin receptor splicing assay is based on alternative splicing of exon11 whose isoform is reduced in DM muscle cultures but increased in wild type muscles. Primers used in this assay were located on exon10 and exon12, flanking the alternatively spliced exon11. This generated RT-PCR products of $167 \mathrm{bp}$ and $131 \mathrm{bp}$ based on inclusion (IR-B) or exclusion of exon11 (IR-A) respectively which was applied to the screening of wild type and DM2 fibroblast lines (figure 1).

The IR splicing assay developed was applied to compound treated DM2 fibroblasts to test its efficacy in reversing $I R$ spliceopathy in DM. Initial application in DM2 fibroblasts showed that Ro 31-8220 treatment was effective in partially rescuing $I R$ splicing as demonstrated by increased IR-B isoform hypericin treatment has no effect. Statistical analysis showed significant difference between wild type IR-B isoform in comparison with treatments and controls (DMSO and untreated) (figure 2).

Another study has demonstrated that muscleblind protein 1 (MBNL1) is misregulated in DM by inclusion of exon 7 in DM cell cultures (16). The analysis of efficacy of PKC inhibitors in reversing the spliceopathy of $M B N L 1$ splicing in DM was performed on compound treated DM2 fibroblasts and controls. Only Ro 31-8220 treatment showed a very slight decrease of $M B N L 1+$ exon7 isoform in comparison with hypericin treatment and DMSO treatments, as well as untreated control (figure 3).

Statistical analysis showed significant difference between Ro-31-8220 treatment with controls and hypericin treatments (figure 4).

\section{DISCUSSION}

Splicing assay is an important parameter for assessing the effect of any potential therapeutic agent in myotonic dystrophy. Recently, quantitative methods have been developed for splicing abnormalities in myotonic dystrophy with a view to applying them for therapeutic screening (24) In DM, MBNL1 is to be defectively spliced at exon7 resulting in the inclusion of this exon in DM patients and its absence in controls $(16,25,26)$. Similarly, $M B N L 2$ shows identical splicing misregulation in exon7 in DM (16). The predominance of $M B N L 1$ splice isoforms 
containing exon7 in DM may account for its localisation in the nucleus (16,25,26). Ro 31-8220 treatment was previously demonstrated to reduce MBNL1 levels in the nuclear fraction from DM1 fibroblast to that seen in nonDM cells (23). It suggests that Ro 31-8220 has effect on correcting MBNL1 missplicing as demonstrated in this study.

DM patients are associated with insulin resistance (diabetes type1) as a result of splicing abnormalities in $I R$. DM1 muscle cultures have been observed to have predominance of IR-A, the non-muscle splice isoform with lower signalling capacity $(13,14)$. The IR-A isoform which lacks exon11 necessary for its biochemical activity was demonstrated to be due to MBNL1 and MBNL2 depletion and/or elevated level of CUG-BP1 in DM1 myoblasts $(27,28,29)$. In addition, DM2 patient muscle display similar $I R$ splicing abnormality found in DM1 (14). The PKC inhibitor Ro 31-8220 demonstrated effects on IR splicing in DM2 fibroblast similar to that of MBNL1 splicing above.

In the screening analysis carried out on spliceopathy of DM2 in this study, only PKC inhibitor Ro 31-8220 treatments showed the potential to alleviate DM2 features for all the defective splicing events in exon 11 of $I R$, exon22 and exon 7 of both $M B N L 1$.

The PKC inhibitor Ro 31-8220 was used in a functional study by Wang et al (2009) to test the role of CUGBP1 in DM in an inducible cardiac-specific mouse model of the disease. Administration of PKC inhibitors to this mouse model was observed to relieve cardiac conduction defects as well as cardiac abnormalities. In addition, these inhibitors were found to reduce misregulated splicing events in exon 21 of Ank2 and exon 16 of Mtmr3 which are specifically regulated by CUG-BP1 (30). Taken together these reports justifies relevance of Ro 31-8220 as a possible therapeutic agent for not only DM1 but DM2 as well.

\section{ACKNOWLEDGEMENTS:}

The author would like to thank Professor David Brook and Christopher Hayes of University of Nottingham for their assistance in compound treatments of cells.

\section{REFERENCES}

1. Harper, P. S. (2001) Myotonic Dystrophy 3rd edition. W. B. Saunders. London.

2. Machuca-Tzili, L., Brook, D. \& Hilton-Jones, D. (2005) Clinical and molecular aspects of the myotonic dystrophies: a review. Muscle Nerve, 32, 1-18.

3. Liquori, C. L., Ricker, K., Moseley, M. L., Jacobsen, J. F., Kress, W., Naylor, S. L., Day, J. W. \& Ranum, L. P. (2001) Myotonic dystrophy type 2 caused by a CCTG expansion in intron 1 of ZNF9. Science, 293, 864-7.

4. Fardaei, M., Larkin, K., Brook, J. D. \& Hamshere, M. G. (2001) In vivo co-localisation of MBNL protein with DMPK expanded-repeat transcripts. Nucleic Acids Res, 29, 2766-71.

5. Fardaei, M., Rogers, M. T., Thorpe, H. M., Larkin, K., Hamshere, M. G., Harper, P. S. \& Brook, J. D. (2002) Three proteins, MBNL, MBLL and MBXL, co-localize in vivo with nuclear foci of expanded-repeat transcripts in DM1 and DM2 cells. Hum Mol Genet, 11, 805-14.

6. Miller, J. W., Urbinati, C. R., Teng-Umnuay, P., Stenberg, M. G., Byrne, B. J., Thornton, C. A. \& Swanson, M. S. (2000) Recruitment of human muscleblind proteins to (CUG)(n) expansions associated with myotonic dystrophy. EMBO J, 19, 4439-48.

7. Mankodi, A., Urbinati, C. R., Yuan, Q. P., Moxley, R. T., Sansone, V., Krym, M., Henderson, D., Schalling, M., Swanson, M. S. \& Thornton, C. A. (2001) Muscleblind localizes to nuclear foci of aberrant RNA in myotonic dystrophy types 1 and 2. Hum Mol Genet, 10, 2165-70.

8. Arambula, J. F., Ramisetty, S. R., Baranger, A. M. \& Zimmerman, S. C. (2009) A simple ligand that selectively targets CUG trinucleotide repeats and inhibits MBNL protein binding. Proc Natl Acad Sci U S A, $106,16068-73$.

9. Gareiss, P. C., Sobczak, K., McNaughton, B. R., Palde, P. B., Thornton, C. A. \& Miller, B. L. (2008) Dynamic combinatorial selection of molecules capable of inhibiting the (CUG) repeat RNA-MBNL1 interaction in vitro: discovery of lead compounds targeting myotonic dystrophy (DM1). J Am Chem Soc, 130, 16254-61.

10. Pushechnikov, A., Lee, M. M., Childs-Disney, J. L., Sobczak, K., French, J. M., Thornton, C. A. \& Disney, M. D. (2009) Rational design of ligands targeting triplet repeating transcripts that cause RNA dominant disease: application to myotonic muscular dystrophy type 1 and spinocerebellar ataxia type 3.J Am Chem Soc, $131,9767-79$.

11. Warf, M. B., Nakamori, M., Matthys, C. M., Thornton, C. A. \& Berglund, J. A. (2009) Pentamidine reverses the splicing defects associated with myotonic dystrophy. Proc Natl Acad Sci U S A, 106, 18551-6.

12. Ranum, L. P. \& Cooper, T. A. (2006) RNA-mediated neuromuscular disorders. Annu Rev Neurosci, 29, 25977.

13. Savkur, R. S., Philips, A. V.\& Cooper, T. A. (2001) Aberrant regulation of insulin receptor alternative splicing is associated with insulin resistance in myotonic dystrophy. Nat Genet, 29, 40-7.

14. Savkur, R. S., Philips, A. V., Cooper, T. A., Dalton, J. C., Moseley, M. L., Ranum, L. P. \& Day, J. W. (2004) 
Insulin receptor splicing alteration in myotonic dystrophy type 2. Am J Hum Genet, 74, 1309-13.

15. Machuca-Tzili, L., Thorpe, H., Robinson, T. E., Sewry, C. \& Brook, J. D. (2006) Flies deficient in Muscleblind protein model features of myotonic dystrophy with altered splice forms of Z-band associated transcripts. Hum Genet, 120, 487-99.

16. Lin, X., Miller, J. W., Mankodi, A., Kanadia, R. N., Yuan, Y., Moxley, R. T., Swanson, M. S. \& Thornton, C. A. (2006) Failure of MBNL1-dependent post-natal splicing transitions in myotonic dystrophy. Hum Mol Genet, 15, 2087-97.

17. Nakamori, M., Kimura, T., Fujimura, H., Takahashi, M. P. \& Sakoda, S. (2007) Altered mRNA splicing of dystrophin in type 1 myotonic dystrophy. Muscle Nerve, 36, 251-7.

18. Philips, A. V., Timchenko, L. T. \& Cooper, T. A. (1998) Disruption of splicing regulated by a CUG-binding protein in myotonic dystrophy. Science, 280, 737-41.

19. Sergeant, N., Sablonniere, B., Schraen-Maschke, S., Ghestem, A., Maurage, C. A., Wattez, A., Vermersch, P. \& Delacourte, A. (2001) Dysregulation of human brain microtubule-associated tau mRNA maturation in myotonic dystrophy type 1. Hum Mol Genet, 10, 2143-55.

20. Buj-Bello, A., Furling, D., Tronchere, H., Laporte, J., Lerouge, T., Butler-Browne, G. S. \& Mandel, J. L. (2002) Muscle-specific alternative splicing of myotubularin-related 1 gene is impaired in DM1 muscle cells. Hum Mol Genet, 11, 2297-307.

21. Kanadia, R. N., Johnstone, K. A., Mankodi, A., Lungu, C., Thornton, C. A., Esson, D., Timmers, A. M., Hauswirth, W. W. \& Swanson, M. S. (2003) A muscleblind knockout model for myotonic dystrophy. Science, $302,1978-80$.

22. Kimura, T., Nakamori, M., Lueck, J. D., Pouliquin, P., Aoike, F., Fujimura, H., Dirksen, R. T., Takahashi, M. P., DulhuntyULHUNTY, A. F. \& SAKODA, S. (2005) Altered mRNA splicing of the skeletal muscle ryanodine receptor and sarcoplasmic/endoplasmic reticulum $\mathrm{Ca} 2+-\mathrm{ATPase}$ in myotonic dystrophy type 1 . Hum Mol Genet, 14, 2189-200.

23. Ketley, A., Chen, C. Z., Li, X., Arya, S., Robinson, T. E., Granados-Riveron, J., Udosen, I., Morris, G. E., Holt, I., Furling, D., Chaouch, S., Haworth, B., Southall, N., Shinn, P., Zheng, W., Austin, C. P., Hayes, C. J. \& Brook, D.(2013) High-content screening identifies small molecules that remove nuclear foci, affect MBNL distribution and CELF1 protein levels via a PKC-independent pathway in myotonic dystrophy cell lines. Human Molecular Genetics 1-12.

24. Wojciechowska, M., Sobczak, K., Kozlowski, P., Sedehizadeh1, S., Wojtkowiak-Szlachcic, A., Czubak, K., Markus, R., Lusakowska, A., Kaminska, A., \& Brook, J. D. (2018) Quantitative Methods to Monitor RNA Biomarkers in Myotonic Dystrophy. Scientific Reports, 8, 1-13.

25. Botta, A., Rinaldi, F., Catalli, C., Vergani, L., Bonifazi, E., Romeo, V., Loro, E., Viola, A., Angelini, C. \& Novelli, G. (2008) The CTG repeat expansion size correlates with the splicing defects observed in muscles from myotonic dystrophy type 1 patients. J Med Genet, 45, 639-46.

26. Cardani, R., Baldassa, S., Botta, A., Rinaldi, F., Novelli, G., Mancinelli, E. \& Meola, G. (2009) Ribonuclear inclusions and MBNL1 nuclear sequestration do not affect myoblast differentiation but alter gene splicing in myotonic dystrophy type 2. Neuromuscul Disord, 19, 335-43.

27. Dansithong, W., Paul, S., Comai, L. \& Reddy, S. (2005) MBNL1 is the primary determinant of focus formation and aberrant insulin receptor splicing in DM1. J Biol Chem, 280, 5773-80.

28. Ho, T. H., Charlet, B. N., Poulos, M. G., Singh, G., Swanson, M. S. \& Cooper, T. A. (2004) Muscleblind proteins regulate alternative splicing. EMBO J, 23, 3103-12.

29. Paul, S., Dansithong, W., Kim, D., Rossi, J., Webster, N. J., Comai, L. \& Reddy, S. (2006) Interaction of muscleblind, CUG-BP1 and hnRNP H proteins in DM1-associated aberrant IR splicing. EMBO J, 25, 427183.

30. Wang, G. S., Kuyumcu-Martinez, M. N., Sarma, S., Mathur, N., Wehrens, X. H. \& Cooper, T. A. (2009) PKC inhibition ameliorates the cardiac phenotype in a mouse model of myotonic dystrophy type 1. J Clin Invest, $119,3797-806$. 


\section{LIST OF FIGURES}
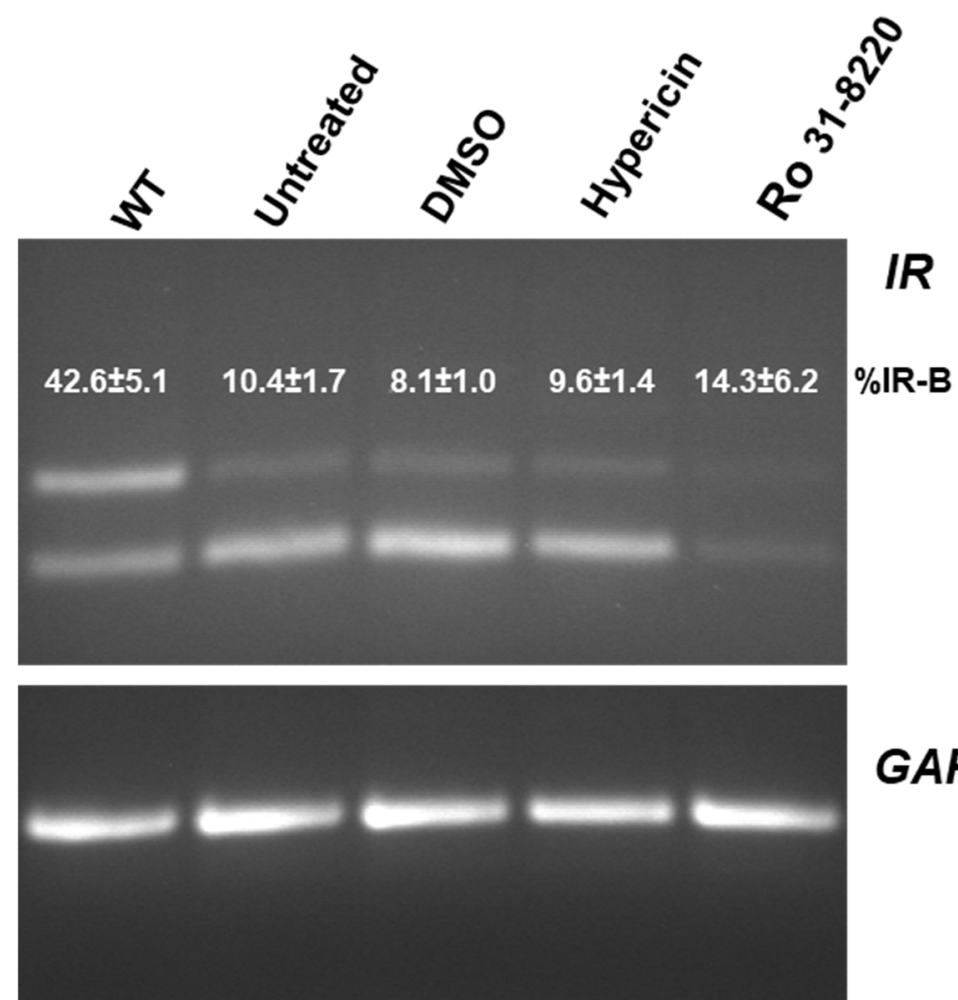

\section{GAPDH}

Figure 1: Ro 31-8220 shows slight reversal of $I R$ splicing defect in DM2 fibroblast as indicated by the increased presence of IR-B isoform. RT-PCR was normalised using GAPDH.

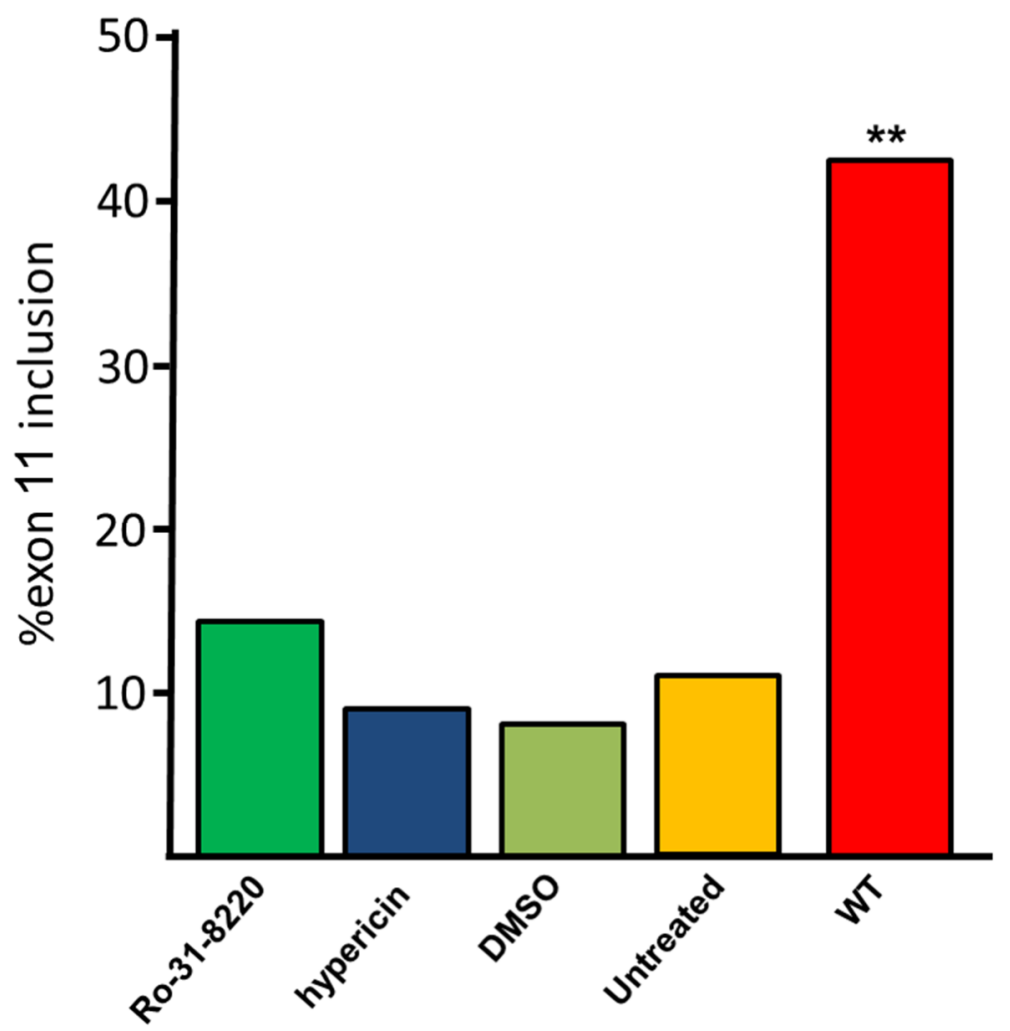

Figure 2: Analysis of $I R$ splice isoforms in DM2 fibroblasts showing effect of PKC inhibitors Ro-31-8220 and hypericin treatments on the proportion of the IR-B isoform. 


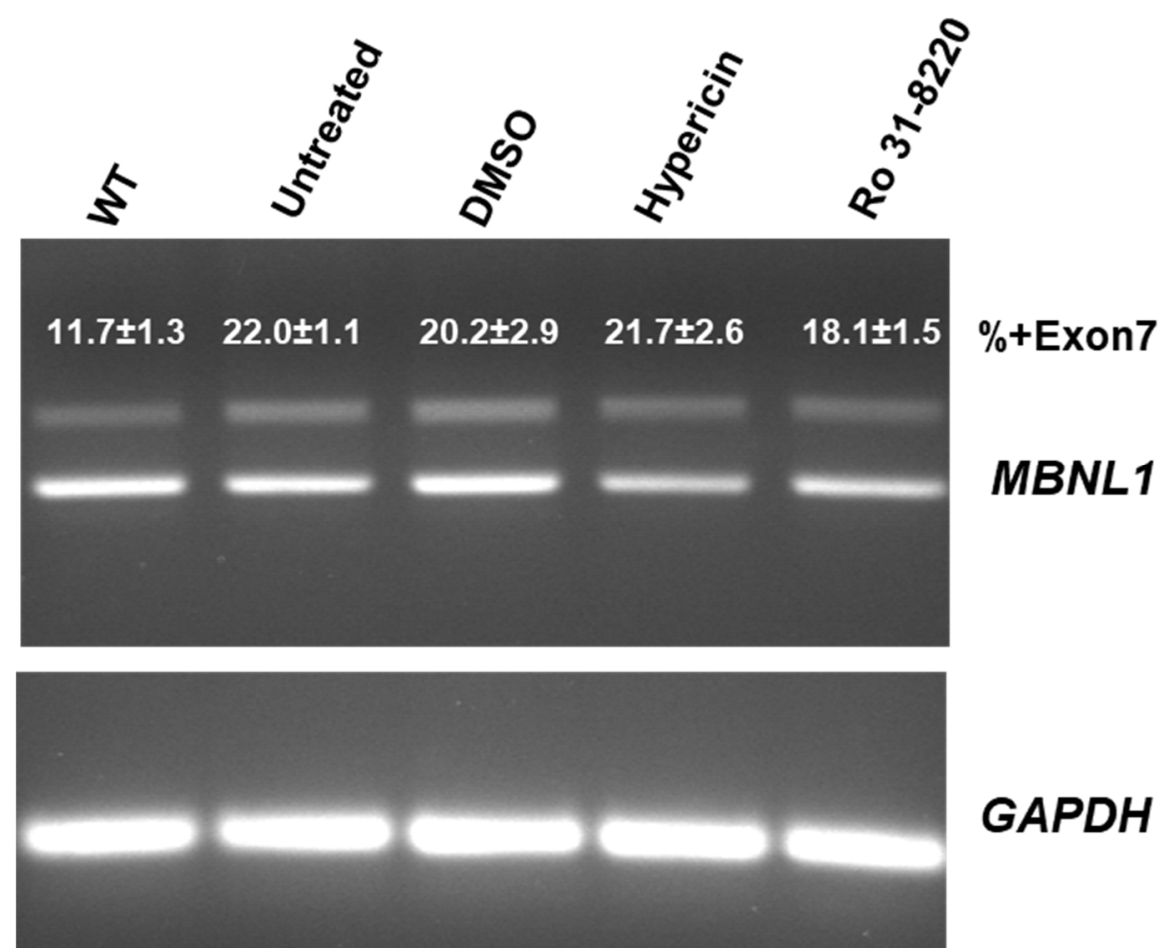

Figure 3: $M B N L 1$ splicing in PKC inhibitor treated DM2 fibroblasts and controls, demonstrating that Ro31-8220 treatments had partial effect on its splicing.

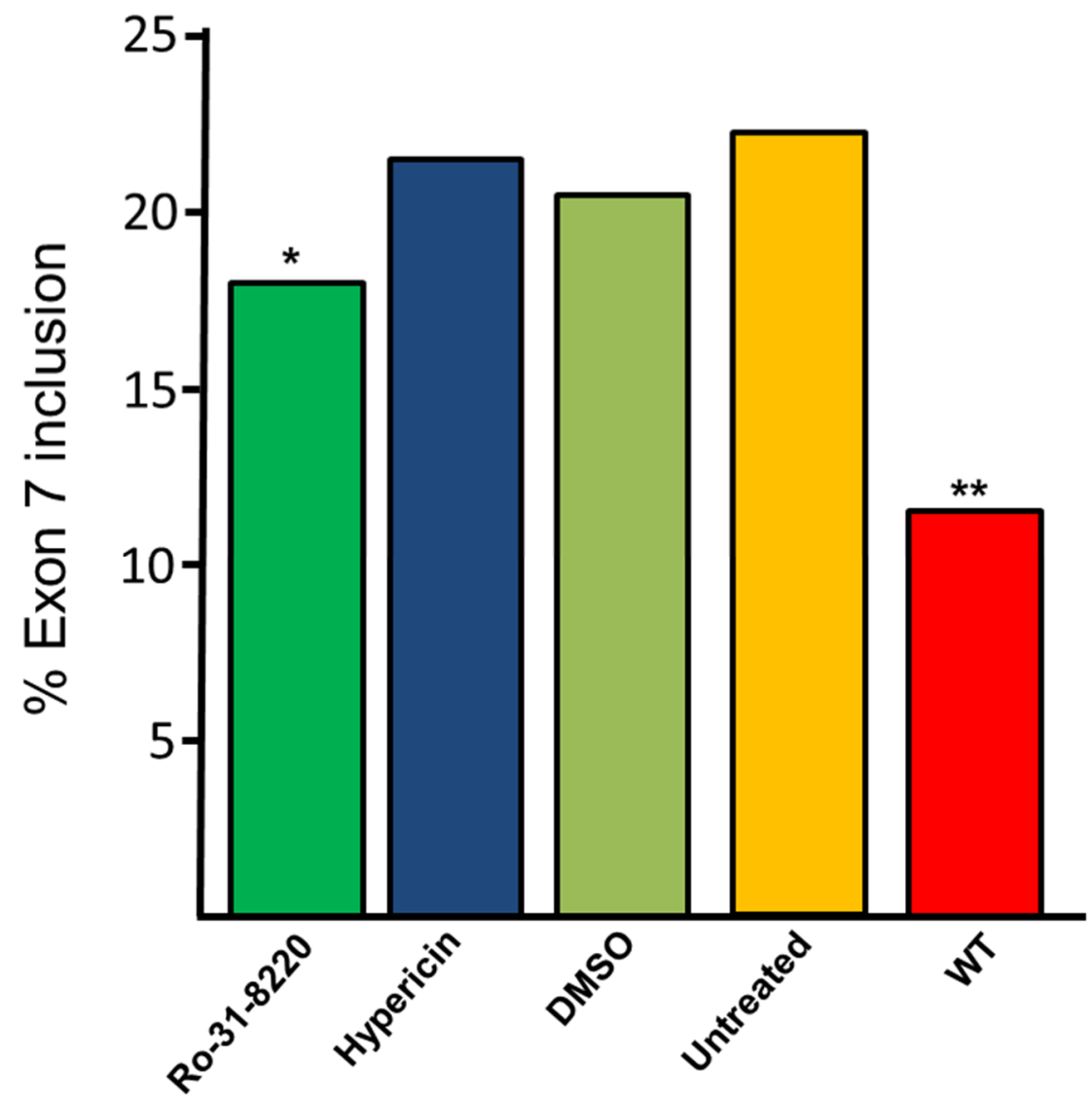

Figure 4: Analysis of Exon 7 inclusion in MBNL1 showing that Ro-31-8220 had effect in on missplicing of $M B N L 1$ comparison with hypericin and untreated control. 